\title{
The impact of temperature vertical structure on trajectory modeling of stratospheric water vapor
}

\author{
T. Wang ${ }^{1,2}$, A. E. Dessler ${ }^{1}$, M. R. Schoeberl ${ }^{3}$, W. J. Randel ${ }^{4}$, and J.-E. Kim ${ }^{5}$ \\ ${ }^{1}$ Texas A\&M University, College Station, Texas, USA \\ ${ }^{2}$ NASA Jet Propulsion Laboratory/California Institute of Technology, Pasadena, California, USA \\ ${ }^{3}$ Science and Technology Corporation, Columbia, Maryland, USA \\ ${ }^{4}$ National Center for Atmospheric Research, Boulder, Colorado, USA \\ ${ }^{5}$ University of Colorado, Boulder, Colorado, USA \\ Correspondence to: T. Wang (tao.wang@jpl.nasa.gov)
}

Received: 28 September 2014 - Published in Atmos. Chem. Phys. Discuss.: 24 November 2014

Revised: 13 March 2015 - Accepted: 17 March 2015 - Published: 31 March 2015

\begin{abstract}
Lagrangian trajectories driven by reanalysis meteorological fields are frequently used to study water vapor $\left(\mathrm{H}_{2} \mathrm{O}\right)$ in the stratosphere, in which the tropical cold-point temperatures regulate the amount of $\mathrm{H}_{2} \mathrm{O}$ entering the stratosphere. Therefore, the accuracy of temperatures in the tropical tropopause layer (TTL) is of great importance for understanding stratospheric $\mathrm{H}_{2} \mathrm{O}$ abundances. Currently, most reanalyses, such as the NASA MERRA (Modern Era Retrospective - analysis for Research and Applications), only provide temperatures with $\sim 1.2 \mathrm{~km}$ vertical resolution in the TTL, which has been argued to miss finer vertical structure in the tropopause and therefore introduce uncertainties in our understanding of stratospheric $\mathrm{H}_{2} \mathrm{O}$. In this paper, we quantify this uncertainty by comparing the Lagrangian trajectory prediction of $\mathrm{H}_{2} \mathrm{O}$ using MERRA temperatures on standard model levels (traj.MER-T) to those using GPS temperatures at finer vertical resolution (traj.GPS-T), and those using adjusted MERRA temperatures with finer vertical structures induced by waves (traj.MER-Twave). It turns out that by using temperatures with finer vertical structure in the tropopause, the trajectory model more realistically simulates the dehydration of air entering the stratosphere. But the effect on $\mathrm{H}_{2} \mathrm{O}$ abundances is relatively minor: compared with traj.MER-T, traj.GPS-T tends to dry air by $\sim 0.1$ ppmv, while traj.MERTwave tends to dry air by $0.2-0.3$ ppmv. Despite these differences in absolute values of predicted $\mathrm{H}_{2} \mathrm{O}$ and vertical dehydration patterns, there is virtually no difference in the interannual variability in different runs. Overall, we find that a tropopause temperature with finer vertical structure has limited impact on predicted stratospheric $\mathrm{H}_{2} \mathrm{O}$.
\end{abstract}

\section{Trajectory model and temperatures used}

Stratospheric water vapor $\left(\mathrm{H}_{2} \mathrm{O}\right)$ and its feedback play an important role in regulating the global radiation budget and the climate system (e.g., Holton et al., 1995; Randel et al., 2006; Solomon et al., 2010; Dessler et al., 2013). It has been known since Brewer's seminal work on stratospheric circulation that tropical tropopause temperature is the main driver of stratospheric $\mathrm{H}_{2} \mathrm{O}$ concentration (Brewer, 1949). As parcels approach and pass through the cold-point tropopause - the altitude at which air temperature is the coldest - condensation occurs and ice falls out, thereby regulating the parcel's $\mathrm{H}_{2} \mathrm{O}$ concentration to the local saturation level (e.g., Fueglistaler et al., 2009, and references therein). This is the dehydration process. The role of tropopause temperature variation in tropical dehydration is most apparent in the annual variation in tropical stratospheric $\mathrm{H}_{2} \mathrm{O}$, also known as the "tape recorder" (Mote et al., 1996).

When air crosses the tropical tropopause layer (TTL), it experiences multiple dehydrations due to encounters with lower temperatures, and the final stratospheric $\mathrm{H}_{2} \mathrm{O}$ mixing ratio is established after air passes through the coldest temperature along its path, which sets the strong relationship between cold-point tropopause and the entry-level $\mathrm{H}_{2} \mathrm{O}$ (e.g., Holton and Gettelman, 2001; Randel et al., 2004, 2006).

The details of the transport and dehydration process can be understood by performing Lagrangian trajectory simulations, which track the temperature history of a large number of individual parcels. Unlike modeling chemical tracers, which depends strongly on the transport imposed (Ploeger et 
al., 2011; Wang et al., 2014), the simulation of $\mathrm{H}_{2} \mathrm{O}$ is primarily constrained by tropopause temperatures. Dehydration thus primarily depends on the air parcel temperature history, and stratospheric $\mathrm{H}_{2} \mathrm{O}$ simulations ultimately require accurate analyses of temperatures particularly in the tropopause (e.g., Mote et al., 1996; Fueglistaler et al., 2005, 2009; Liu et al., 2010; Schoeberl and Dessler, 2011; Schoeberl et al., 2012, 2013).

In this paper, we use a forward, domain-filling trajectory model to study the detailed dehydration behavior of the humidity of air parcels entering the tropical lower stratosphere. Previous analyses have demonstrated that this model can accurately simulate many aspects of the observed stratospheric $\mathrm{H}_{2} \mathrm{O}$ (Schoeberl and Dessler, 2011; Schoeberl et al., 2012, 2013). Despite the good agreements with observations, there are clear areas of uncertainties from, for instance, the accuracy of circulation fields (Schoeberl et al., 2012), the details of the dehydration mechanisms (Schoeberl et al., 2014), the influences from convection (Schoeberl and Dessler, 2011; Schoeberl et al., 2014), and the impacts from temperature vertical structures in the TTL, etc. In this paper, we investigate uncertainties introduced by the last one - the effect of vertical structures of temperatures.

This is accomplished by comparing trajectory results from using NASA Modern Era Retrospective - analysis for Research and Applications (MERRA) (Rienecker et al., 2011) temperatures on standard model levels to using temperatures with finer vertical structures, which include GPS temperatures at finer vertical resolution and the MERRA temperatures adjusted to account for finer vertical structure induced by waves (Kim and Alexander, 2013). This will help us to further understand the importance of the vertical structure of tropopause temperatures in dehydrating air entering the stratosphere.

\section{Trajectory model and temperatures used}

\subsection{Trajectory model}

The trajectory model used here follows the details described in Schoeberl and Dessler (2011), with parcel positions integrated using the Bowman trajectory code (Bowman, 1993; Bowman et al., 2013). This model has been proven capable of simulating stratospheric $\mathrm{H}_{2} \mathrm{O}$ and its long-term variability (Schoeberl and Dessler, 2011; Schoeberl et al., 2012, 2013; Dessler et al., 2014), modeling chemical tracer transport in the lower stratosphere (Wang et al., 2014), and studying the stratospheric air age spectrum (Ray et al., 2014). Because of the overly dispersive behavior of kinematic trajectories (e.g., Schoeberl et al., 2003; Liu et al., 2010; Ploeger et al., 2010; Schoeberl and Dessler, 2011), we perform diabatic trajectories using isentropic coordinates, in which the vertical velocity is the potential temperature tendency converted from the diabatic heating rates via the thermodynamic equation (e.g., Andrews et al., 1987). Here we used total heating rates, which include heating due to long-wave and short-wave radiation, moist physics, vertical diffusion, and friction drag.

The parcel initiation level is chosen to be the $370 \mathrm{~K}$ isentrope, which is above the level of zero radiative heating ( 355-365 K, Gettelman and Forster, 2002) but below the tropical tropopause $(\sim 375-380 \mathrm{~K})$. Every day, parcels are initialized on equal-area grids covering $40^{\circ} \mathrm{N}-40^{\circ} \mathrm{S}$ and advected forward in time by reanalysis winds. At the end of each day, any parcels that have descended below the $345 \mathrm{~K}$ $(\sim 250 \mathrm{hPa}$ or $\sim 10 \mathrm{~km})$ level are removed since in most cases they have entered the troposphere. The upper boundary is chosen to be $2200 \mathrm{~K}$ isentrope $(\sim 1 \mathrm{hPa}$ or $\sim 50 \mathrm{~km})$ to cover the entire stratosphere. Parcels are initialized and added to the ensemble consecutively on every day and the combined set of parcels is then advected forward. This process is repeated over the entire integration period so that after 2-3 years the stratospheric domain is filled up with parcels - this is the concept of domain-filling, which guarantees a robust statistics.

$\mathrm{H}_{2} \mathrm{O}$ is conserved along the trajectories except when saturation occurs; in that case, excess $\mathrm{H}_{2} \mathrm{O}$ is instantaneously removed from the parcel to keep the relative humidity with respect to ice from exceeding $100 \%$. This is sometimes referred as "instant dehydration" (e.g., Schoeberl et al., 2014), which ignores detailed microphysics but has shown to simulate many features of $\mathrm{H}_{2} \mathrm{O}$ in the lower stratosphere (e.g., Fueglistaler et al., 2005; Jensen and Pfister, 2004; Gettelman et al., 2002). We chose the $100 \%$ saturation level because (1) different saturation levels offset the simulated $\mathrm{H}_{2} \mathrm{O}$ constant values but with identical interannual variability; and (2) the focus of the paper is to investigate the uncertainty introduced by using different temperatures, which would be the same as long as we keep the same criteria for different runs.

In addition to $\mathrm{H}_{2} \mathrm{O}$, we also carry methane $\left(\mathrm{CH}_{4}\right)$ concentration for each parcel. We initiate $\mathrm{CH}_{4}$ values increased from $1.76 \mathrm{ppmv}$ in 2006 to $1.83 \mathrm{ppmv}$ in 2013. As described in Schoeberl and Dessler (2011), we use photochemical loss rates supplied from Goddard two-dimensional stratospheric chemistry model (Fleming et al., 2007) to convert each methane molecule into two molecules of $\mathrm{H}_{2} \mathrm{O}$ (Dessler et al., 1994). Note that our analysis focuses on the tropical lower stratosphere, where methane oxidation has little impacts on the total $\mathrm{H}_{2} \mathrm{O}$ abundances (Fig. 6 in Schoeberl et al., 2012).

Along each trajectory, we locate the point where air experiences the coldest temperature as the final dehydration point (FDP), which determines the stratosphere entry-level $\mathrm{H}_{2} \mathrm{O}$ mixing ratio $\left(\mathrm{FDP} \mathrm{H}_{2} \mathrm{O}\right)$ for that trajectory. As will be shown below, the entry-level $\mathrm{H}_{2} \mathrm{O}$ predicted by the trajectory model is affected by the vertical structures in the temperature field.

\subsection{Temperature data sets}

In this paper, we use MERRA (Rienecker et al., 2011) circulation to advect parcels. This includes horizontal wind com- 
ponents and total diabatic heating rates. As shown in Schoeberl et al. $(2012,2013)$, the trajectory model driven by this reanalysis yields excellent estimates of $\mathrm{H}_{2} \mathrm{O}$ compared to observations by the Aura Microwave Limb Sounder (MLS) (Read et al., 2007).

Driven by the same circulation, trajectory runs using three different temperature data sets are compared to quantify the uncertainties induced by different vertical structures of temperatures: (1) using MERRA standard temperatures on model levels (MER-T), denoted as traj.MER-T; (2) using GPS radio occultation (RO) temperatures (GPS-T), denoted as traj.GPS-T; and (3) using MERRA temperatures adjusted to have finer vertical structures induced by waves (MERTwave) (Kim and Alexander, 2013), denoted as traj.MERTwave. Note that MERRA does not assimilate GPS observations, which makes the two temperature data sets independent from each other. Trajectory runs with the three different temperature data sets are summarized in Table 1.

\subsubsection{GPS temperature}

Owing to its high vertical resolution, GPS temperature profiles capture the cold-point tropopause with high accuracy. In this paper, we use GPS wet profile (wetPrf) retrieved at $100 \mathrm{~m}$ vertical resolution using a one-dimensional variational technique based on ECMWF analysis. The wetPrf and GPS atmospheric profile (atmPrf, derived assuming no water vapor in the air) temperatures are essentially the same at 200$10 \mathrm{hPa}$, but at altitudes lower than the $200 \mathrm{hPa}$ level the errors in atmPrf could be as high as $\sim 3 \mathrm{~K}$ due to neglect of water vapor (Das and Pan, 2014). Despite being retrieved at $100 \mathrm{~m}$ resolution, the actual vertical resolution ranges from $0.5 \mathrm{~km}$ in the lower troposphere to $\sim 1 \mathrm{~km}$ in the middle atmosphere (Kursinski et al., 1997).

The GPS radio occultation (RO) technique makes the data accuracy independent of platforms. That could make the biases among different RO payloads as low as $0.2 \mathrm{~K}$ in the tropopause and stratosphere (Ho et al., 2009). Therefore, to compensate for the relatively lower horizontal resolution (relative to that of reanalysis), we include GPS RO from all platforms. This includes the Constellation Observing System for Meteorology, Ionosphere, and Climate (COSMIC) (Anthes et al., 2008), the CHAllenging Minisatellite Payload (CHAMP) satellite (Wickert et al., 2001), the Communications/Navigation Outage Forecasting System (CNOFS), the Gravity Recovery And Climate Experiment (GRACE) twin satellites (Beyerle et al., 2005), the Meteorological Operational Polar Satellite - A (MetOp-A), the Satellite de Aplicaciones Cientifico-C (SACC) satellite (Hajj et al., 2004), and the TerraSAR-X (TerraSAR-X). There are $\sim 2000-3500$ profiles per day, mostly from COSMIC, with $\sim 700-1100$ profiles of these in the tropics.

Each day, GPS temperature profiles are binned to $200 \mathrm{~m}$ vertical resolution. Horizontally, we grid data into $2.5 \times 1.25$ (longitude by latitude) grids with 2-D Gaussian function
Table 1. Different temperature data sets used in trajectory model.

\begin{tabular}{lllll}
\hline $\begin{array}{l}\text { Temperature } \\
\text { data sets }\end{array}$ & Availability & $\begin{array}{l}\text { Horizontal } \\
\text { resolution } \\
\text { longitude } \times \\
\text { latitude }\end{array}$ & $\begin{array}{l}\text { Vertical } \\
\text { resolution } \\
\text { in TTL }\end{array}$ & $\begin{array}{l}\text { Trajectory } \\
\text { runs } \\
\text { denoted }\end{array}$ \\
\hline MER-T & Daily* & $2 / 3 \times 1 / 2$ & $\sim 1.2 \mathrm{~km}$ & traj.MER-T \\
GPS-T (gridded) & Daily & $2.5 \times 1.25$ & $0.2 \mathrm{~km}$ & traj.GPS-T \\
MER-Twave & Daily* & $2 / 3 \times 1 / 2$ & $0.2 \mathrm{~km}$ & traj.MER-Twave \\
\hline $\begin{array}{l}\text { * These data sets are available at a 6-hourly resolution, but for fair comparison with using GPS data, we } \\
\text { used daily averages. }\end{array}$
\end{tabular}

weighting. This gridded data set has been successfully used in diagnosing many detailed features of the tropopause inversion layer (Gettelman and Wang, 2015). We use over 7 years of GPS data available from July 2006 to December 2013, and the trajectory run using it is denoted as traj.GPS-T.

Figure 1 shows a snapshot of the $100 \mathrm{hPa}$ GPS raw (panel a) and gridded (panel b) temperature on 1 January 2010, compared with MERRA temperature (panel c). It demonstrates that the gridded GPS temperature captures most of the features, although some detailed structure might be lost due to its relatively sparse sampling.

Figure 2 shows the GPS and MERRA temperatures in the TTL (panel a) and their differences (GPS-MERRA) (panel b, extended to $31 \mathrm{hPa})$ averaged over the deep tropics $\left(18^{\circ} \mathrm{S}-\right.$ $18^{\circ} \mathrm{N}$ ) during the GPS period. Here we examine the values at the MERRA model levels (large dots) as well as MERRA in-between levels (small dots), where both GPS and MERRA temperatures are linearly interpolated to the same pressure levels. It shows that on average GPS is at most $\sim 0.4 \mathrm{~K}$ colder than MERRA around the cold-point tropopause, where temperature is $\sim 193 \mathrm{~K}$ at $\sim 93 \mathrm{hPa}$ (between MERRA coarse levels). This translates to at most a $0.4 \mathrm{ppmv}$ wet bias in the entry-level of stratospheric $\mathrm{H}_{2} \mathrm{O}$, assuming $100 \%$ saturation level in our model. Note that the GPS temperatures at MERRA levels 100 and $85 \mathrm{hPa}$ could be lower than that in MERRA if we average over $10^{\circ} \mathrm{S}-10^{\circ} \mathrm{N}$, but it does not change the fact that MERRA is always warm biased around the cold-point tropopause.

\subsubsection{MERRA temperature adjusted by waves}

Wave-induced disturbances on tropopause temperatures are underrepresented by current reanalyses (Kim and Alexander, 2013). At the reanalysis model levels, temperature variability at timescales shorter than $\sim 10$ days are weaker than radiosonde observations (see Fig. 1b-d in Kim and Alexander, 2013). Those underrepresented waves include a part of the spectrum of Kelvin waves, mixed Rossby-gravity waves, and gravity waves. When using those model level temperatures in trajectory simulations, conventional interpolation in the vertical (under time domain), either linear or higher order, further degrades temperature structures due to averaging of waves with different phases. 

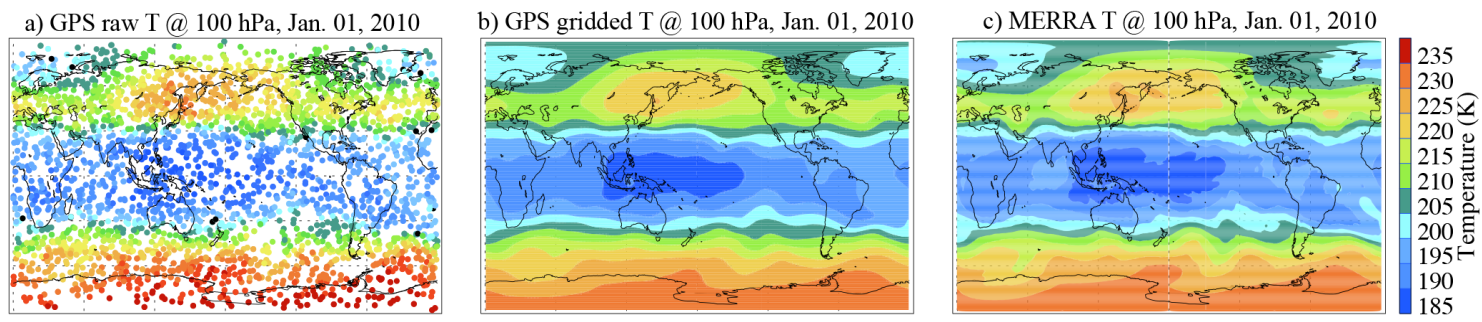

Figure 1. Comparison of temperatures from raw GPS (a), gridded GPS (b), and MERRA temperature (c) at $100 \mathrm{hPa}$ on 1 January 2010.
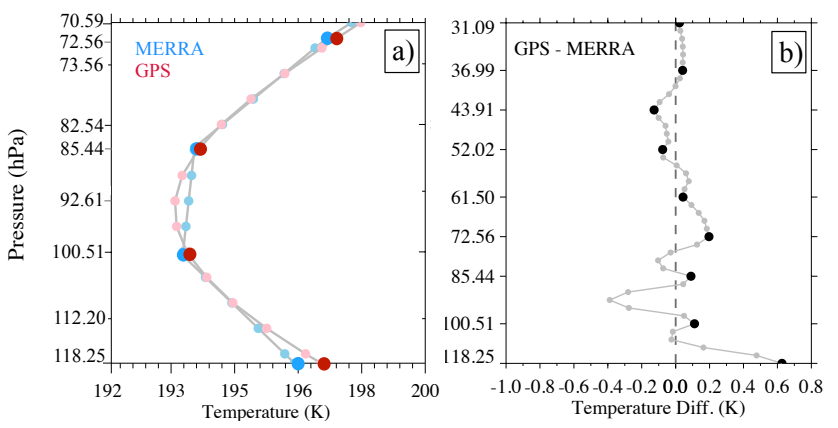

Figure 2. (a) MERRA (blue) and GPS (red) mean temperature in TTL and (b) their differences (GPS-MERRA) extended to $31 \mathrm{hPa}$. All values are averaged over the deep tropics $\left(18^{\circ} \mathrm{S}-18^{\circ} \mathrm{N}\right)$ in 2007-2013, with larger dots marking the MERRA model levels and small dots marking the MERRA in-between levels, where both GPS and MERRA temperatures are linearly interpolated to the same pressure levels.

To overcome these limitations, a scheme developed by Kim and Alexander, based on wave amplification from radiosonde observations and frequency-domain interpolation, has been proven effective in recovering subseasonal (less than 90 days) wave-induced variability and creating wave-like vertical structures in reanalysis temperatures (see Kim and Alexander, 2013, for more details). Applying this scheme to MERRA temperature records yields a new MERRA temperature data set (MER-Twave) that has finer vertical structure induced by waves (see Fig. 3 in Kim and Alexander, 2013). The trajectory simulation using this temperature data set is denoted as traj.MER-Twave.

Note that we only considered the vertical structure issue, since it is by far a limiting factor in representing waves in the TTL. A large portion of the TTL wave spectrum has horizontal and temporal scales much larger and longer than reanalysis resolution; therefore, temperature behaves almost linearly between model horizontal and temporal resolution. However, temperature does not behave linearly in vertical space due to the fact that a significant portion of TTL waves have vertical wavelengths shorter than $\sim 4 \mathrm{~km}$ (see Fig. S4 in the Supplement of Kim and Alexander, 2015), which could make wave-induced disturbances less represented by the $\sim 1.2 \mathrm{~km}$ vertical resolution in reanalyses.

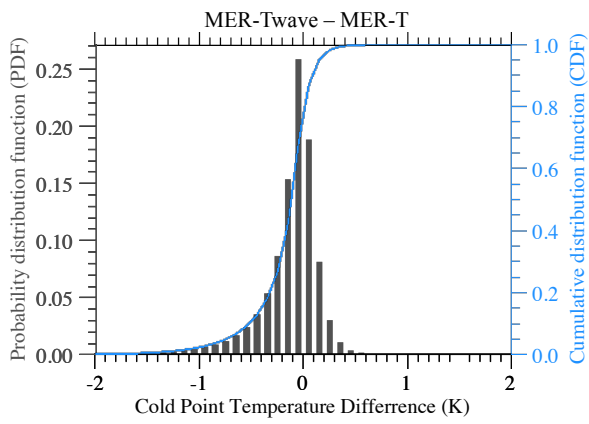

Figure 3. Cold-point temperature differences between MERRA adjusted by waves and MERRA (MER-Twave-MER-T) during 20072013. The probability density function in black is plotted on the left $y$ axis and cumulative distribution function in blue on the right $y$ axis.

The wave scheme produces both positive and negative perturbations to the MERRA temperature profiles, depending on the phase of waves. Overall, the change in the temperature induced by waves is less than $2 \mathrm{~K}$ (Fig. 3), although in rare cases it can reach 5-7 K. Importantly, however, about $80 \%$ of the changes in cold-point temperature are negative, with the wave scheme lowering the average cold-point temperatures by $\sim 0.35 \mathrm{~K}$. It is this reduction in cold-point temperature that is responsible for the reduction in $\mathrm{H}_{2} \mathrm{O}$ entering the stratosphere.

In our study, we included both GPS and MER-Twave data sets because they have their own advantages and limitations. GPS provides sparse sampling in the tropics (only $\sim 700$ 1100 profiles per day over $30^{\circ} \mathrm{N}-30^{\circ} \mathrm{S}$ ), indicating a smaller variability in GPS than likely exists, but the mean temperatures are more accurate. In contrast, MER-Twave has better variability but not an accurate mean, since it is designed to have similar variability to radiosondes but with a mean kept as with the original MER-T. In summary, the mean temperature is closer to reality in GPS than in MER-T and MERTwave, but the temperature variability is closer to reality in MER-Twave than in MER-T and GPS. In addition, the MERTwave is a general technique that can be applied to situations where GPS temperatures are not available (e.g., reanalyses before 2006, climate models). 

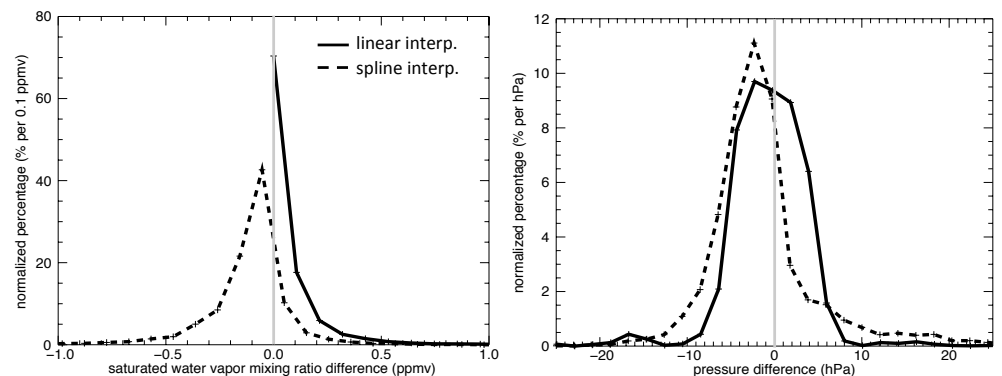

Figure 4. Probability density functions of the differences between linear and cubic spline interpolations from the actual value form the GPS temperature profiles. Left: minimum saturation mixing ratio of the profile (units are percent per 0.1 ppmv); right: pressure of the saturation mixing ratio minimum (units are percent per $1 \mathrm{hPa}$ ). The plus signs in each line mark the bin intervals.

\subsubsection{Interpolation scheme}

In our study, we use linear interpolation to estimate the temperature between the fixed levels of temperature data sets. However, some previous analyses have used higher-order interpolations, such as cubic spline (e.g., Liu et al., 2010), to make assumptions about the strong curvature of temperature profiles around the cold-point tropopause. In order to determine which approach is superior, we sample GPS tropical temperature profiles at MERRA vertical levels and then use the two interpolation schemes to reconstruct the full GPS resolution. Then we compare the minimum saturation mixing ratio from the recovered profiles to the minimum calculated from the full-resolution GPS profiles.

Figure 4 (left panel) shows the probability distribution of the differences between the minimum saturation mixing ratio in the full-resolution GPS profile and in the two interpolation schemes. On average, the linear interpolation performs better (RMSD is 0.18 and 0.25 ppmv for the linear and cubic spline, respectively). Figure 4 (right panel) shows the corresponding probability distribution of the difference of the pressure of this minimum, and the linear interpolation does better for this metric too (RMSD is 5.2 and $7.2 \mathrm{hPa}$ for the linear and the cubic spline interpolation, respectively). We have also tested higher-order spline interpolations and find that they do not produce lower RMSE than linear interpolation. Overall, the cubic spline interpolation tends to underestimate cold-point temperature, making the implied $\mathrm{H}_{2} \mathrm{O}$ too dry, as noted by Liu et al. (2010). Thus, in our study, we adopted linear interpolation scheme for three different trajectory runs.

\section{Trajectory results}

\subsection{Dehydration patterns}

The gridded GPS temperatures have been available since July 2006, so for fair comparison we start all trajectory runs at that time and run them forward till the end of 2013. For each model run, we calculate statistics of the final dehydration points (FDP) for all parcels entering the stratosphere.
We define "parcels entering the stratosphere" as parcels that underwent final dehydration between $45^{\circ} \mathrm{N}$ and $45^{\circ} \mathrm{S}$ (thus ignoring polar dehydration) and that were already at altitudes higher (pressure lower) than $90 \mathrm{hPa}$ for at least 6 months since the last time they were dehydrated (FDP). This guarantees that the parcels had already crossed the cold-point tropopause ( $\sim 380 \mathrm{~K}$ or $\sim 100-94 \mathrm{hPa})$ and had indeed experienced the coldest temperature along their ascending paths. Averaging over 7 years minimizes the effects of interannual variability.

Figure 5a-c compare the FDP frequency (solid lines) and the $\mathrm{FDP} \mathrm{H}_{2} \mathrm{O}$ (dashed lines) in different seasons among three runs. As mentioned, the FDP $\mathrm{H}_{2} \mathrm{O}$ can be understood as the stratosphere entry level of $\mathrm{H}_{2} \mathrm{O}$. In all cases, it is clear that dehydration occurs almost exclusively between 110 and $60 \mathrm{hPa}$. The average FDP $\mathrm{H}_{2} \mathrm{O}$ reaches a minimum at $85 \mathrm{hPa}$ for all runs, meaning parcels dehydrated in its vicinity carry the smallest amount of $\mathrm{H}_{2} \mathrm{O}$ into the stratosphere. The relatively high FDP $\mathrm{H}_{2} \mathrm{O}$ above $80 \mathrm{hPa}$ (just above the entry level) comes from the parcels that avoided the tropical cold trap and experienced final dehydration at higher, warmer levels of the stratosphere. Out of $\sim 1.3$ million parcels in the stratosphere, there are only $\sim 0.3 \%$ bypassed the cold-point tropopause, and these parcels have little impact on stratosphere water vapor.

The FDP frequency, however, shows large differences among three runs. The run using MERRA temperature (traj.MER-T) yields an annual bimodal FDP maxima distinctly at 98 and $84 \mathrm{hPa}$ (Fig. 5a solid black lines), close to the MERRA model levels 100.5 and $85.4 \mathrm{hPa}$, respectively. The bimodal feature comes from averages between single, prominent peaks during DJF (December-JanuaryFebruary, Fig. 5a, blue) and JJA (June-July-August, Fig. 5a, red), when cold-point tropopause is close to a particular level (DJF to $85 \mathrm{hPa}$ and JJA to $100 \mathrm{hPa}$ ) in MERRA (Fig. 5d-e black bars), as well as averages between bi-modal peaks during MAM (March-April-May, Fig. 5a, green) and SON (September-October-November, Fig. 5a, yellow), when tropopause temperature in the real atmosphere falls between the two MERRA levels (Fig. 5f red bars). The dehy- 

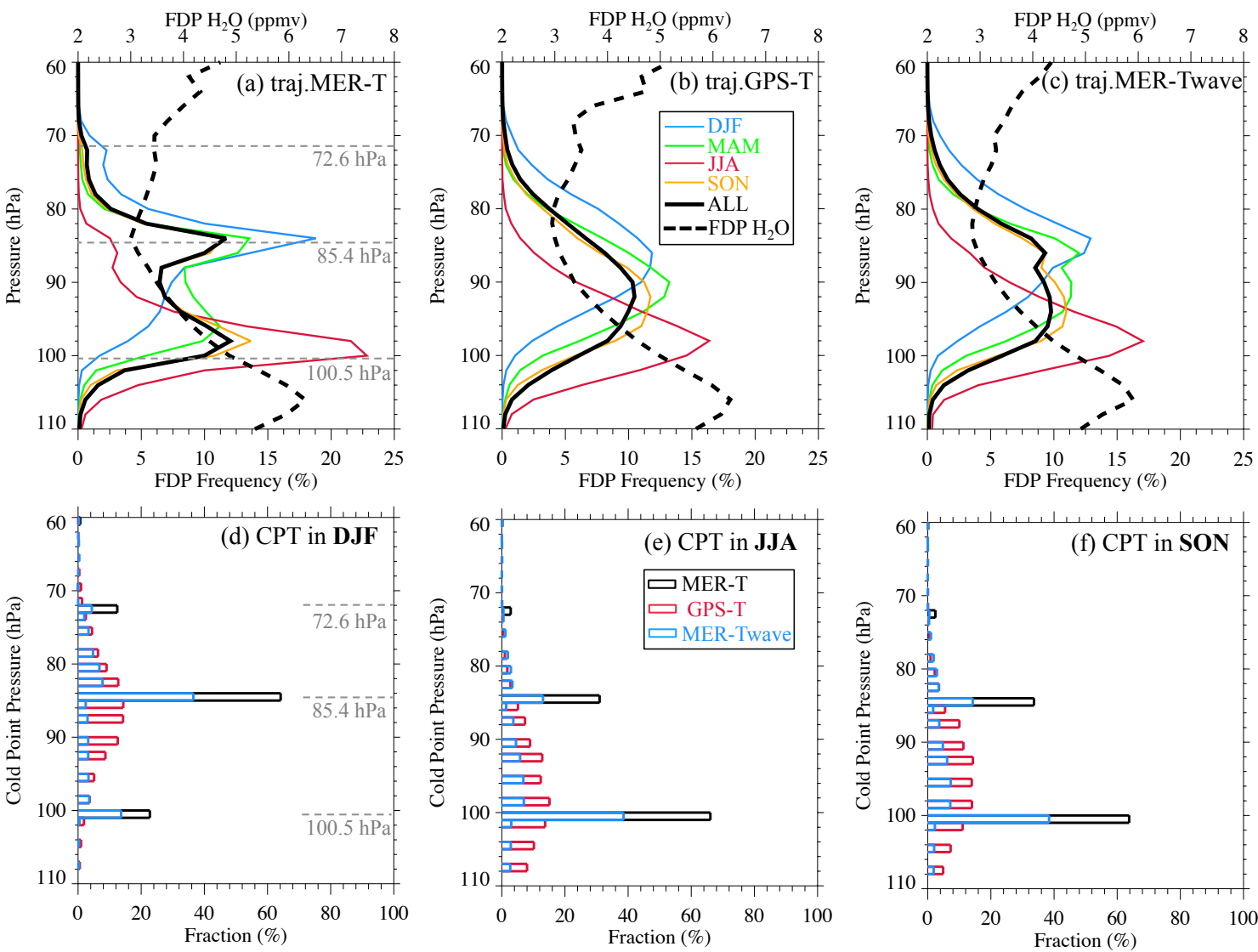

Figure 5. Seasonal FDP vertical distributions (in percentage, first row solid lines, lower $x$ axes) and FDP saturation mixing ratio (FDP $\mathrm{H}_{2} \mathrm{O}$, i.e., the stratosphere entry-level $\mathrm{H}_{2} \mathrm{O}$, ppmv, first row dashed lines, upper $x$ axes) from trajectory simulations using (a) MERRA temperatures, (b) GPS temperatures, and MERRA temperatures adjusted by waves (c), compared to the cold point tropopause (CPT) statistics (second row) during (d) DJF, (e) JJA, and (f) SON. The FDP frequency is normalized by total FDP events, so each solid curve adds up to $100 \%$. The MERRA model levels are marked in (a) and (d).
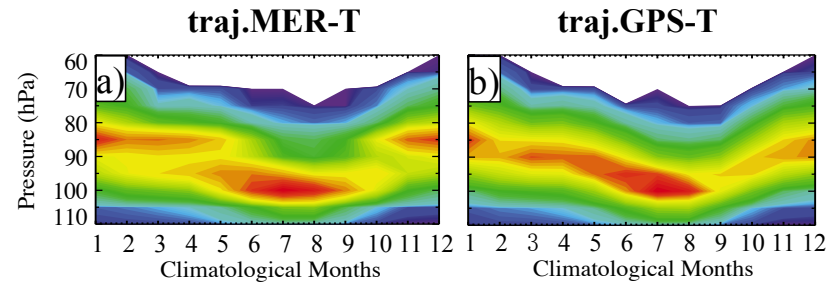

traj.MER-Twave
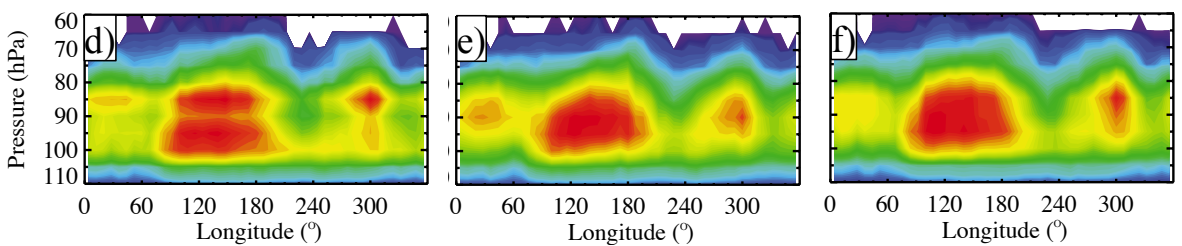

Normalized FDP Frequency

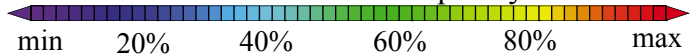

Figure 6. Vertical distributions of normalized FDP events in time-evolutional (a-c) views among trajectory simulations by using (a) MERRA temperature (traj.MER-T), (b) GPS RO temperature (traj.GPS-T), and (c) MERRA temperature adjusted by waves (traj.MER-Twave). The longitudinal variations of FDP are highlighted in $(\mathbf{d}-\mathbf{f})$ to emphasize the FDP discontinuity in traj.MER-T. All panels are plotted in their own range and color-coded at the same percentiles (i.e., $0,20,40, \ldots 100 \%$ ) to compare the patterns. 


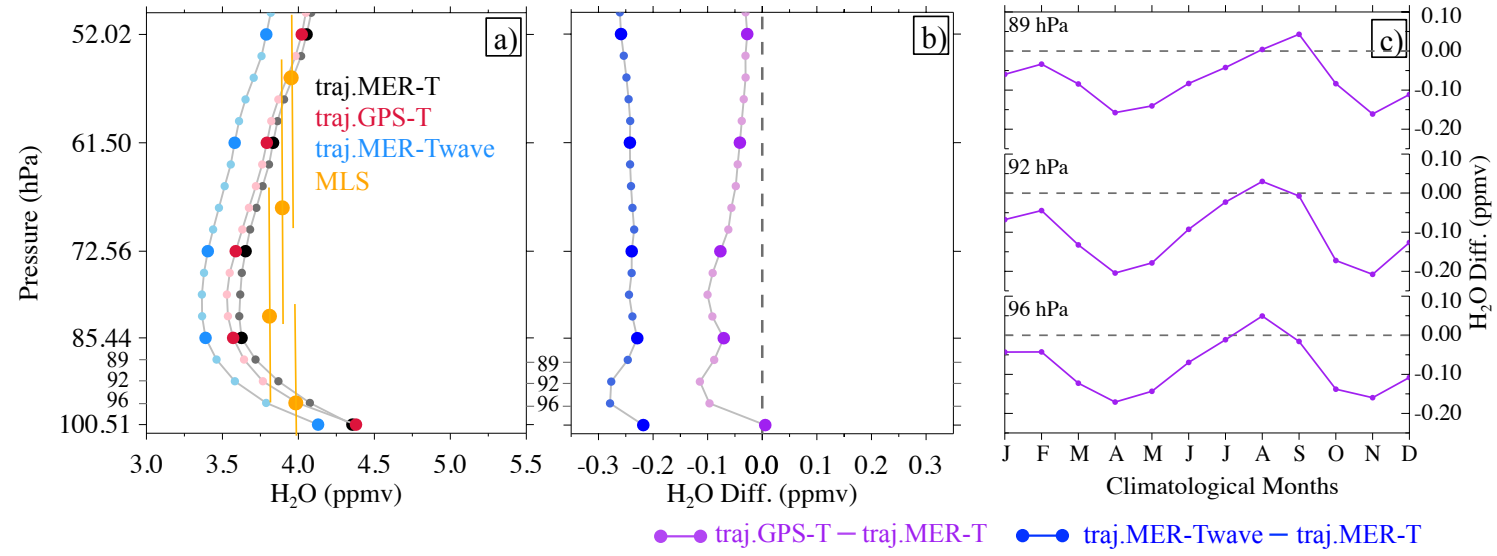

Figure 7. (a) Trajectory predicted $\mathrm{H}_{2} \mathrm{O}$ compared with MLS observations (the vertical bars in orange indicate the MLS vertical resolutions at each of the MLS retrieval pressure levels); (b) trajectory $\mathrm{H}_{2} \mathrm{O}$ differences induced by waves (blue) and by using GPS temperatures (purple); (c) annual differences at 96,92 , and $89 \mathrm{hPa}$. All values are averaged over the deep tropics $\left(18^{\circ} \mathrm{S}-18^{\circ} \mathrm{N}\right)$ in $2007-2013$, with larger dots marking the MERRA model levels and small dots marking the MERRA in-between levels - the levels where the cold-point tropopause could have been found but were not available in the current MERRA vertical resolution.

dration profiles implied from using the other two data sets, however, experience smoothed changes due to gradual variations of cold-point altitudes in each season (red and blue bars in Fig. 5d-f). It is clear that physically more realistic dehydrations (Fig. 5b-c) occur with using tropopause temperatures in finer vertical structures (Fig. 5d-f red and blue bars).

Note that at FDP, the coldest temperature encountered could be either at or in-between MERRA model levels, depending on the trajectory integration intervals. If we suppose our trajectory integration time step is on the order of seconds, then at some time steps, parcels would inevitably travel to each of the MERRA model levels, and therefore the encountered coldest temperatures would always be at one of the two levels in MERRA. In other words, the bimodal FDP distribution from MERRA run (Fig. 5a) could be even more peaked when choosing a smaller integration step in our trajectories. There are two reasons that we did not choose such smaller time step: (1) the wind and temperature data are only available 6-hourly or even daily resolution (GPS) so a much smaller time step introduces more uncertainties with more interpolation; and (2) considering the balance between model efficiency and computational resources.

Figure 6 depicts the vertical distributions of normalized FDP in time (panels a-c) and longitude (panels d-f) sectors for the three different runs. We see that the MERRA coarse model levels do not capture the variations of coldpoint tropopause well during MAM and SON, resulting in discontinuous transition of FDP from DJF to MAM, and from JJA to SON (panel a). When using GPS temperatures (panel b) and MERRA temperatures adjusted to bear finer vertical structures (panel c), the dehydration patterns show continuous variations throughout the year. The bimodal feature is more emphasized in the longitudinal-vertical view (panel d), where we can also see that throughout the year the most frequent dehydrations occur over the western tropical Pacific region.

\subsection{Water vapor $\left(\mathrm{H}_{2} \mathrm{O}\right)$}

It is obvious that trajectory simulations using GPS temperatures (traj.GPS-T) and MERRA temperatures adjusted by waves (traj.MER-Twave) tend to yield more reasonable FDP patterns around the cold-point tropopause (Fig. 5a-c solid lines), although the parcels dehydrated at particular altitudes have similar amounts of $\mathrm{H}_{2} \mathrm{O}$ in all three models (FDP $\mathrm{H}_{2} \mathrm{O}$, Fig. 5a-c dashed lines). A more interesting question is whether different dehydration occurrences affect the stratospheric $\mathrm{H}_{2} \mathrm{O}$ predicted by the trajectory model.

Figure 7 a shows the tropical $\left(18^{\circ} \mathrm{N}-18^{\circ} \mathrm{S}\right) \mathrm{H}_{2} \mathrm{O}$ profile predicted from three trajectory runs compared with MLS observations. The vertical bars in MLS indicate the MLS vertical resolutions at each of the MLS retrieval pressure levels. Here we see clearly that the $\mathrm{H}_{2} \mathrm{O}$ in stratosphere reflects the different cold-point temperatures in three data sets. The differences induced by temperatures with finer vertical structures are clearly shown in Fig. 7b, where we see slightly drier air expected in GPS run since GPS temperatures are at most $\sim 0.4 \mathrm{~K}$ lower than that of MERRA around the tropopause (Fig. 2), whereas wave perturbations produce air $0.2-0.3 \mathrm{ppmv}$ drier, in agreement with previous calculations (e.g., Jensen and Pfister, 2004; Schoeberl et al., 2011).

Figure $8 \mathrm{c}$ also shows that compared to traj.MER-T, the dry biases from using GPS temperatures are largest during MAM and SON (0.14-0.21 ppmv on average), when the real coldpoint tropopause cannot be resolved by the MERRA model levels. During DJF and JJA, when the cold point is near one of the two MERRA standard levels (Fig. 5d-e), the differ- 


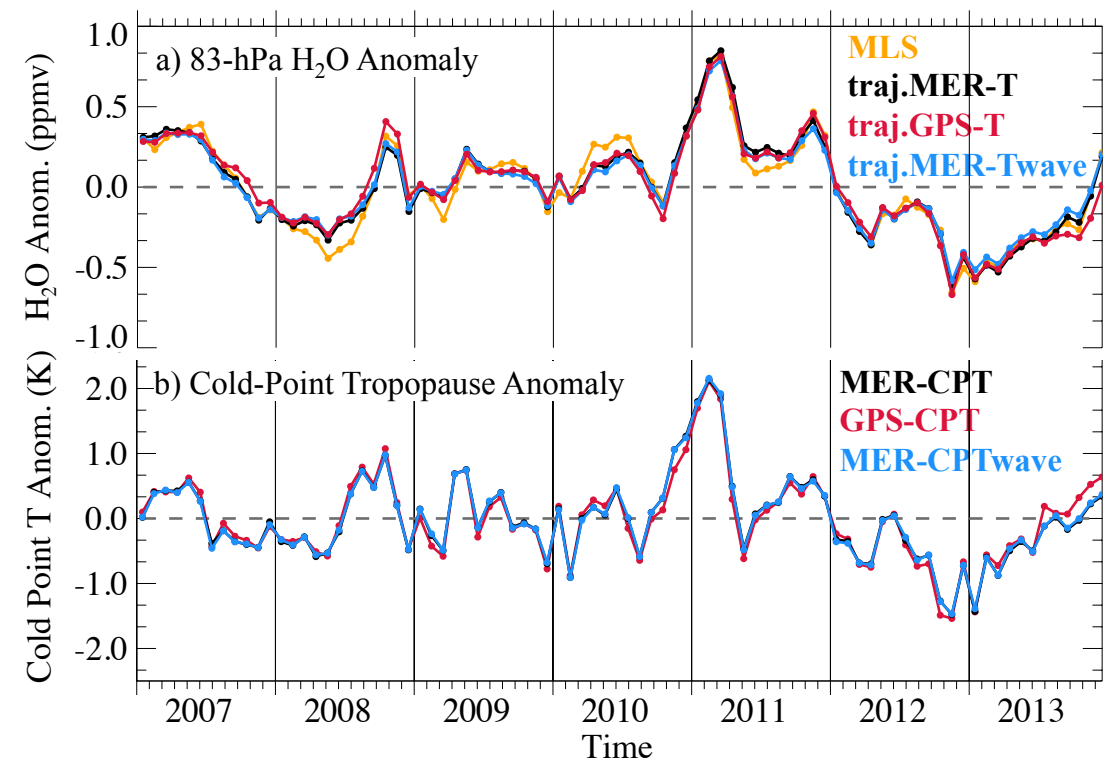

Figure 8. (a) Trajectory simulated $\mathrm{H}_{2} \mathrm{O}$ anomalies compared with the MLS observations; and (b) cold-point temperature anomalies from three temperature data sets. All time series are averaged over the deep tropics $\left(18^{\circ} \mathrm{N}-18^{\circ} \mathrm{S}\right)$. All trajectory results in panel a are weighted by the MLS averaging kernels for fair comparison.

ences become smaller. Thus we conclude that using GPS-T and MER-Twave decreases simulated stratospheric $\mathrm{H}_{2} \mathrm{O}$ by an average of $\sim 0.11$ and 0.28 ppmv, respectively, accounting for $\sim 2.5$ and $7 \%$ changes given typical stratospheric $\mathrm{H}_{2} \mathrm{O}$ abundances of $\sim 4$ ppmv.

It is important to point out that, despite these differences in the absolute value of $\mathrm{H}_{2} \mathrm{O}$, there is virtually no difference in the anomalies (residual from the average annual cycle). In Fig. 8a, we compare the time series of $\mathrm{H}_{2} \mathrm{O}$ anomalies at $83 \mathrm{hPa}$ from the three different trajectory runs weighted by the MLS averaging kernels to the MLS $\mathrm{H}_{2} \mathrm{O}$ observations. Note that the interannual variations of approximately \pm 0.5 ppmv in $\mathrm{H}_{2} \mathrm{O}$ are in good agreement with the interannual changes of about $\pm 1 \mathrm{~K}$ in cold-point tropopause temperatures (Fig. 8b) for all three different runs, further supporting that the stratospheric entry level of $\mathrm{H}_{2} \mathrm{O}$ and cold-point tropopause temperature are strongly coupled (e.g., Randel et al., 2004, 2006; Randel and Jensen, 2013). We also compared traj.MER-T and traj.MER-Twave over a longer period (19852013), and it shows almost no differences in interannual variability either. Clearly, for studying the interannual variability of $\mathrm{H}_{2} \mathrm{O}$, MERRA temperatures in coarse vertical resolution are as good as temperatures at finer vertical resolution.

\section{Summary}

The dehydration of air entering the stratosphere largely depends on the cold-point temperature around the tropopause. This may not be represented accurately by reanalyses due to their relatively coarse vertical resolution that reports coarser temperature vertical structure. To investigate the impacts of this, we compare trajectory results from using standard MERRA temperatures at coarse model levels (traj.MER-T) to those using GPS temperatures in higher vertical resolution (traj.GPS-T) and those using adjusted MERRA temperatures with finer vertical structures induced by waves (traj.MERTwave).

Driven by the same MERRA circulation, with a $100 \%$ saturation assumption we find that on average traj.GPS-T dries the stratospheric $\mathrm{H}_{2} \mathrm{O}$ prediction by $\sim 0.1 \mathrm{ppmv}$ and traj.MER-Twave dries it by $\sim 0.2-0.3$ ppmv (Fig. $7 \mathrm{a}-\mathrm{b}$ ), accounting for at most $\sim 2.5 \%$ and $7.5 \%$ of changes given typical stratospheric $\mathrm{H}_{2} \mathrm{O}$ abundances of $\sim 4$ ppmv, respectively. However, despite the differences in $\mathrm{H}_{2} \mathrm{O}$ abundances, the interannual variability (residual from the mean annual cycle) exhibits virtually no differences due to the strong coupling between the interannual changes of stratospheric $\mathrm{H}_{2} \mathrm{O}$ and tropical cold-point tropopause temperatures (Fig. 8). Therefore, in terms of studying the interannual changes of stratospheric $\mathrm{H}_{2} \mathrm{O}$, we argue that reanalysis temperatures are more useful due to their long-term availability. 
Looking at the locations of FDP, we find a bimodal distribution when using standard MERRA temperatures on model levels (Figs. 5-6). This is caused by the fact that the coldpoint tropopause is constrained to be near the two MERRA model levels (100.5 and $85.4 \mathrm{hPa}$ ) that bracket the cold-point tropopause (Fig. 5d-f). When using the temperatures with finer vertical structures, the resultant FDP patterns appear to be more physically reasonable (Figs. 5a-c and 6).

In this paper, we perform linear interpolations for all trajectory runs. Other analyses have used cubic spline interpolation owing to the strong curvature of temperature profile around the cold-point tropopause. We investigate the performances of both schemes using GPS temperature profiles (Sect. 2.2.3) and find that while introducing new information due to its assumption in the temperature profile around the tropopause, the cubic spline scheme tends to generate unrealistically low cold-point temperatures due to cubic fitting. Therefore, the results are not necessarily realistic and, additionally, the linear interpolation is more accurate overall (Fig. 4).

It is well known that TTL temperatures regulate stratospheric humidity. In this paper, we have investigated one issue in our understanding of TTL temperatures - the effect of finer vertical structure in tropopause temperatures - and find that it is comparatively minor. This provides some confidence that the trajectory model driven by current modern reanalyses is capable of depicting the stratospheric water vapor accurately.

Acknowledgements. The authors thank Kenneth Bowman, Joan Alexander, Sun Wong, and Eric Jensen for their helpful discussions and comments. This work was supported by NSF AGS-1261948, NASA grant NNX13AK25G and NNX14AF15G, and partially by the NASA Aura Science Program. This work was partially carried out during visits of Tao Wang funded by the Graduate Student Visitor Program under the Advanced Study Program (ASP) at the National Center for Atmospheric Research (NCAR), which is operated by the University Corporation for Atmospheric Research, under the sponsorship of the National Science Foundation.

Edited by: P. Jöckel

\section{References}

Andrews, D. G., Holton, J. R., and Leovy, C. B.: Middle Atmosphere Dynamics, Academic Press, Orlando, Florida, 489 pp., 1987.

Anthes, R. A., Ector, D., Hunt, D. C., Kuo, Y.-H., Rocken, C., Schreiner, W. S., Sokolovskiy, S. V., Syndergaard, S., Wee, T.K., Zeng, Z., Bernhardt, P. A., Dymond, K. F., Chen, Y., Liu, H., Manning, K., Randel, W. J., Trenberth, K. E., Cucurull, L., Healy, S. B., Ho, S.-P., McCormick, C., Meehan, T. K., Thompson, D. C., and Yen, N. L.: The COSMIC/FORMOSAT-
3 mission: Early results, B. Am. Meteorol. Soc., 89, 313-333, doi:10.1175/BAMS-89-3-313, 2008.

Beyerle, G., Schmidt, T., Michalak, G., Heise, S., Wickert, J., and Reigber, Ch.: GPS radio occultation with GRACE: Atmospheric profiling utilizing the zero difference technique, Geophys. Res. Lett., 32, L13806, doi:10.1029/2005GL023109, 2005.

Bowman, K. P.: Large-scale isentropic mixing properties of the Antarctic polar vortex from analyzed winds, J. Geophys. Res., 98, 23013-23027, 1993.

Bowman, K. P., Lin, J. C., Stohl, A., Draxler, R., Konopka, P., Andrews, A., and Brunner, D.: Input data requirements Lagrangian Trajectory Models, B. Am. Meteorol. Soc., 94, 10511058, doi:10.1175/BAMS-D-12-00076.1, 2013.

Brewer, A. W.: Evidence for a world circulation provided by the measurements of helium and water vapor distribution in the stratosphere, Q. J. Roy. Meteorol. Soc., 75, 351-363, 1949.

Das, U. and Pan, C. J.: Validation of FORMOSAT-3/COSMIC level 2 "atmPrf" global temperature data in the stratosphere, Atmos. Meas. Tech., 7, 731-742, doi:10.5194/amt-7-731-2014, 2014.

Dessler, A. E., Weinstock, E. M., Hintsa, E. J., Anderson, J. G., Webster, C. R., May, R. D., Elkins, J. W., and Dutton, G. S.: An examination of the total hydrogen budget of the lower stratosphere, Geophys. Res. Lett., 21, 2563-2566, 1994.

Dessler, A. E., Schoeberl, M. R., Wang, T., Davis, S. M., and Rosenlof, K. H.: Stratospheric water vapor feedback, P. Natl. Acad. Sci. USA, 110, 18087-18091, doi:10.1073/pnas.1310344110, 2013.

Dessler, A. E., Schoeberl, M. R., Wang, T., Davis, S. M., and Rosenlof, K. H., Vernier, J.-P.: Variations of Stratospheric Water Vapor Over the Past Three Decades, J. Geophys. Res., 119, 12588-12598, doi:10.1002/2014JD021712, 2014.

Fleming, E. L., Jackman, C. H., Weisenstein, D. K., and Ko, M. K. W.: The impact of interannual variability on multidecadal total ozone simulations, J. Geophys. Res., 112, D10310, doi:10.1029/2006JD007953, 2007.

Fueglistaler, S., Bonazzola, M., Haynes, P. H., and Peter, T.: Stratospheric water vapor predicted from the Lagrangian temperature history of air entering the stratosphere in the tropics, J. Geophys. Res., 110, D08107, doi:10.1029/2004JD005516, 2005.

Fueglistaler, S., Dessler, A. E., Dunkerton, T. J., Folkins, I., Fu, Q., and Mote, P. W.: The tropical tropopause layer, Rev. Geophys., 47, RG1004, doi:10.1029/2008RG000267, 2009.

Gettelman, A. and Forster, P. M. de F.: Definition and climatology of the tropical tropopause layer, J. Meteorol. Soc. Jpn., 80, $911-$ 924, 2002.

Gettelman, A. and Wang, T.: Structural diagnostics of the tropopause inversion layer and its evolution, J. Geophys. Res.Atmos., 120, 46-62, doi:10.1002/2014JD021846, 2015.

Gettelman, A., Randel, W. J., Wu, F., and Massie, S. T.: Transport of water vapor in the tropical tropopause layer, Geophys. Res. Lett., 29, 9.1-9.4, doi:10.1029/2001GL013818, 2002.

Hajj, G. A., Ao, C. O., Iijima, B. A., Kuang, D., Kursinski, E. R., Mannucci, A. J., Meehan, T. K., Romans, L. J., de La Torre Juarez, M., and Yunck, T. P.: CHAMP and SAC-C atmospheric occultation results and intercomparisons, J. Geophys. Res., 109, D06109, doi:10.1029/2003JD003909, 2004.

Ho, S.-P., Goldberg, M., Kuo, Y.-H., Zou, C.-Z., and Schreiner, W.: Calibration of temperature in the lower stratosphere from mi- 
crowave measurements using COSMIC radio occultation data: Preliminary results, Terr. Atmos. Ocean. Sci., 20, 87-100, 2009.

Holton, J. R. and Gettelman, A.: Horizontal transport and the dehydration of the stratosphere, Geophys. Res. Lett., 28, 2799-2802, doi:10.1029/2001GL013148, 2001.

Holton, J. R., Haynes, P. H., McIntyre, M. E., Douglass, A. R., Rood, R. B., and Pfister, L.: Stratosphere-troposphere exchange, Rev. Geophys., 334, 405-439, 1995.

Jensen, E. and Pfister, L.: Transport and freeze-drying in the tropical tropopause layer, J. Geophys. Res., 109, D02207, doi:10.1029/2003JD004022, 2004.

Kim, J.-E. and Alexander, J. M.: A new wave scheme for trajectory simulations of stratospheric water vapor, Geophys. Res. Lett., 40, 5286-5290, doi:10.1002/grl.50963, 2013.

Kim, J.-E. and Alexander, J. M.: Direct impacts of waves on tropical cold point tropopause temperature, Geophys. Res. Lett., online first, doi:10.1002/2014GL062737, 2015.

Kursinski, E. R., Hajj, G. A., Schofield, J. T., Linfield, R. P., and Hardy, K. R.: Observing Earth's atmosphere with radio occultation measurements using the Global Positioning System, J. Geophys. Res., 102, 23429-23465, doi:10.1029/97JD01569, 1997.

Liu, Y. S., Fueglistaler, S., and Haynes, P. H.: Advectioncondensation paradigm for stratospheric water vapor, J. Geophys. Res., 115, D24307, doi:10.1029/2010jd014352, 2010.

Mote, P. W., Rosenlof, K. H., McIntyre, M. E., Carr, E. S., Gille, J. C., Holton, J. R., Kinnersley, J. S., Pumphrey, H. C., Russell III, J. M., and Waters, J. W.: An atmospheric tape recorder: the imprint of tropical tropopause temperatures on stratospheric water vapor, J. Geophys. Res., 101, 3989-4006, 1996.

Ploeger, F., Konopka, P., Günther, G., Grooß, J.-U., and Müller, R.: Impact of the vertical velocity scheme on modeling transport across the tropical tropopause layer, J. Geophys. Res., 115, D03301, doi:10.1029/2009JD012023, 2010.

Ploeger, F., Fueglistaler, S., Grooß, J.-U., Günther, G., Konopka, P., Liu, Y.S., Müller, R., Ravegnani, F., Schiller, C., Ulanovski, A., and Riese, M.: Insight from ozone and water vapour on transport in the tropical tropopause layer (TTL), Atmos. Chem. Phys., 11, 407-419, doi:10.5194/acp-11-407-2011, 2011.

Randel, W. J. and Jensen, E. J.: Physical processes in the tropical tropopause layer and their role in a changing climate, Nat. Geosci., 6, 169-176, doi:10.1038/ngeo1733, 2013.

Randel, W. J., Wu, F., Oltmans, S. J., Rosenlof, K. H., and Nedoluha, G. E.: Interannual Changes of Stratospheric Water Vapor and Correlations with Tropical Tropopause Temperatures, J. Atmos. Sci., 61, 2133-2148, doi:10.1175/15200469(2004)061<2133:ICOSWV>2.0.CO;2, 2004.

Randel, W. J., Wu, F., Vömel, H., Nedoluha, G. E., and Forster, P.: Decreases in stratospheric water vapor after 2001: Links to changes in the tropical tropopause and the Brewer-Dobson circulation, J. Geophys. Res., 111, D12312, doi:10.1029/2005JD006744, 2006.

Ray, E. A., Moore, F. L., Rosenlof, K. H., Davis, S. M., Sweeney, C., Tans, P., Wang, T., Elkins, J. W., Bönisch, H., Engel, A., Sugawara, S., Nakazawa, T., and Aoki, S.: Improving stratospheric transport trend analysis based on SF6 and $\mathrm{CO}_{2}$ measurements, J. Geophys. Res., 119, 14110-14128, doi:10.1002/2014JD021802, 2014.
Read, W. G., Lambert, A., Backmeister, J., Cofield, R. E., Christensen, L. E., Cuddy, D. T., Daffer, W. H., Drouin, B. J., Fetzer, E., Froidevaux, L., Fuller, R., Herman, R., Jarnot, R. F., Jiang, J. H., Jiang, Y. B., Kelly, K., Knosp, B. W., Pumphrey, H. C., Rosenlof, K. H., Sabounchi, X., Santee, M. L., Schwartz, M. J., Snyder, W. V., Stek, P. C., Su, H., Takacs, L. L., Thurstans, R. P., Vomel, H., Wagner, P. A., Waters, J. W., Webster, C. R., Weinstock, E. M., and Wu, D. L.: Aura Microwave Limb Sounder upper tropospheric and lower stratospheric $\mathrm{H}_{2} \mathrm{O}$ and relative humidity with respect to ice validation, J. Geophys. Res., 112, D24S35, doi:10.1029/2007JD008752, 2007.

Rienecker, M. M., Suarez, M. J., Gelaro, R., Todling, R., Bacmeister, J., Liu, E., Bosilovich, M. G., Schubert, S. D., Takacs, L., Kim, G.-K., Bloom, S., Chen, J., Collins, D., Conaty, A., da Silva, A., Gu, W., Joiner, J., Koster, R. D., Lucchesi, R., Molod, A., Owens, T., Pawson, S., Pegion, P., Redder, C. R., Reichle, R., Robertson, F. R., Ruddick, A. G., Sienkiewicz, M., and Woollen, J.: MERRA - NASA's modern-era retrospective analysis for research and applications, J. Climate, 24, 3624-3648, doi:10.1175/JCLI-D-11-00015.1, 2011.

Schoeberl, M. R. and Dessler, A. E.: Dehydration of the stratosphere, Atmos. Chem. Phys., 11, 8433-8446, doi:10.5194/acp11-8433-2011, 2011.

Schoeberl, M. R., Douglass, A. R., Zhu, Z. X., and Pawson, S.: A comparison of the lower stratospheric age spectra derived from a general circulation model and two data assimilation systems, J. Geophys. Res., 108, 4113, doi:10.1029/2002JD002652, 2003.

Schoeberl, M. R., Dessler, A. E., and Wang, T.: Simulation of stratospheric water vapor and trends using three reanalyses, Atmos. Chem. Phys., 12, 6475-6487, doi:10.5194/acp-12-6475-2012, 2012.

Schoeberl, M. R., Dessler, A. E., and Wang, T.: Modeling upper tropospheric and lower stratospheric water vapor anomalies, Atmos. Chem. Phys., 13, 7783-7793, doi:10.5194/acp-13-77832013, 2013.

Schoeberl, M. R., Dessler, A. E., Wang, T., Avery, M. A., and Jensen, E. J.: Cloud Formation, Convection, and Stratospheric Dehydration, Earth Space Sci., 1, 1-17, doi:10.1002/2014EA000014, 2014.

Solomon, S., Rosenlof, K. H., Portmann, R. W., Daniel, J. S., Davis, S. M., Sanford, T. J., and Plattner, G.-K.: Contributions of stratospheric water vapor to decadal changes in the rate of global warming, Science, 327, 1219-1223, 2010.

Wang, T., Randel, W. J., Dessler, A. E., Schoeberl, M. R., and Kinnison, D. E.: Trajectory model simulations of ozone $\left(\mathrm{O}_{3}\right)$ and carbon monoxide (CO) in the lower stratosphere, Atmos. Chem. Phys., 14, 7135-7147, doi:10.5194/acp-14-7135-2014, 2014.

Wickert, J., Reigber, C., Beyerle, G., König, R., Marquardt, C., Schmidt, T., Grundwaldt, L., Galas, R., Meehan, T. K., Melbourne, W. G., and Hocke, K.: Atmosphere sounding by GPS radio occultation: First results from CHAMP, Geophys. Res. Lett., 28, 3263-3266, 2001. 